\title{
UTOPÍA Y REALIDAD DEL DERECHO INTERNACIONAL HUMANITARIO EN COSME DE LA TORRIENTE Y PERAZA ENTRE 1917 Y 1920
}

\section{UTOPIC AND REALITY AT THE HUMANITARIAN INTERNATIONAL RIGHT IN COSME DE LA TORRIENTE Y PERAZA BETWEEN 1917 AND 1920}

\author{
Paul Sarmiento Blanco* \\ Leidiedis Góngora Cruz**
}

\section{RESUMEN}

El presente artículo tiene como objetivo dilucidar la huella dejada por el destacado jurista internacionalista cubano Cosme de la Torriente y Peraza en los marcos del Senado cubano durante el contexto de la Primera Guerra Mundial. Desde diferentes dimensiones del Derecho Internacional Humanitario (DIH) de aquella época, de la Torriente y Peraza actuó dentro del legislativo cubano en el contexto adverso de franco dominio imperialista sobre Cuba y guerra imperialista. Por otro lado, se dan a conocer sus concepciones y acciones acerca la cooperación internacional como parte del DIH en ese periodo, sustentadas en la doctrina de la gratitud hacia los Estados Unidos y en la intención de buscar la consolidación de la personalidad internacional de la república cubana.

\begin{abstract}
PALABRAS CLAVE: CUBA * DERECHO HUMANITARIO * COOPERACIÓN INTERNACIONAL * DERECHO INTERNACIONAL * GUERRA MUNDIAL
\end{abstract}

\section{ABSTRACT}

The purpose of the present article is reveal the print left by the exceptional jurist Cuban internationalist Cosme de la Torriente y Peraza in the marks of the Cuban Senate during the context of the First World War. Since dissimilar dimensions of the Humanitarian International Right of that time, de la Torriente $y$ Peraza it acted inside the Cuban legislative in the antagonist context of truthful imperialistic domain about Cuba and

Universidad de Holguín, Cuba. psarmiento@fh.uho.edu.cu

** Universidad de Holguín, Cuba. lgongora@fh.uho.edu.cu 
imperialistic war. On the other hand, we are given to know his conceptions and actions about international cooperation as part of the DIH in that period, sustained in the doctrine of the gratefulness toward the United States and in the intention of looking for the consolidation of the international personality of the Cuban republic.

KEYWORDS: CUBA * HUMANITARIAN LAW * INTERNATIONAL COOPERATION * INTERNATIONAL LAW * WORLD WAR

\section{INTRODUCCIÓN}

El presente trabajo tiene como objetivo dilucidar la huella dejada por el destacado jurisconsulto e internacionalista cubano Cosme de la Torriente y Peraza (1872-1956) dentro del Senado cubano, en los años de la Primera Guerra Mundial ( $\mathrm{PGM}$ ) desde diversas dimensiones del Derecho Internacional Humanitario (DiH). La importancia de este radica en que dentro de la historiografía cubana no se ha privilegiado este tipo de estudios que socialice los espacios públicos de debate en una época compleja para Cuba como lo fue esta guerra, desde la perspectiva de un problema en la arena internacional, en una república que no era del todo soberana.

Además, se le ha dado poco tratamiento a las dinámicas del pensamiento cubano dentro de un espacio de debate tan importante para la época como era el Senado de la República como parte del poder legislativo cubano. El trabajo analiza los antecedentes necesarios - desde la perspectiva teórica e histórica - para comprender la entrada de Cuba en este primer conflicto mundial $y$ sus principales motivaciones desde diferentes esferas. Para la investigación, se privilegiaron las actas de sesiones del Senado de la República, en específico entre 1917 y 1918; se consultaron esencialmente algunos de los principales discursos de Cosme de la Torriente y Peraza que enfilaron el análisis de problemas internacionales $y$ en especial, sus concepciones del derecho internacional $y$ del рiн en específico, teniendo en cuenta el contexto y las principales concepciones teóricas de la época.

De esta forma, se entiende el contexto particular en que una personalidad tan compleja y dinámica como Cosme de la Torriente y Peraza actuó dentro del legislativo cubano en una época de franco dominio imperialista sobre Cuba. Por otro lado, se dan a conocer y se interpretan sus concepciones de la cooperación internacional en ese contexto sustentadas en la doctrina de la gratitud hacia los Estados Unidos $y$ sus criterios humanistas como bases de su comprensión de las normas del Diн que en aquellas circunstancias podían aplicarse.

\section{BASES TEÓRICAS: DERECHO INTERNACIONAL HUMANITARIO, COOPERACIÓN INTERNACIONAL E IDEOLOGÍA POLÍTICA}

Teóricamente, el DiH es una rama del Derecho Internacional Público que busca delimitar los efectos de los conflictos armados protegiendo a las personas que no participan directamente en estos o que han decidido dejar de participar en el enfrentamiento, así como restringir y regular los medios y métodos de guerra a disposición de los combatientes. El DIH regula la conducta en los conflictos armados a través de normas. Se compone de una serie de reglas, en su mayoría reflejadas en los Convenios de Ginebra de 1949 y sus protocolos adicionales (Moré, 2007).

$\mathrm{Su}$ origen se remonta a las normas dictadas por las antiguas civilizaciones y religiones. La guerra siempre estuvo sujeta a ciertas leyes y costumbres. El más importante antecedente del Dir actual es el Tratado de Armisticio y Regularización de la Guerra, suscrito y ratificado en 1820 entre las autoridades del entonces gobierno de la Gran Colombia y el Jefe de las Fuerzas Expedicionarias de la Corona Española, en la ciudad venezolana de Santa Ana de Trujillo. Este Tratado fue suscrito en el marco del conflicto de la Independencia, siendo el primero en su género en Occidente (Halajczuk y Moya, 1999).

Los cánones del DiH procuran sortear y limitar el sufrimiento humano en épocas de 
conflictos armados, además, intentan delimitar o prohibir el uso de ciertos métodos de guerra; pero no determina si un país tiene derecho a recurrir a la fuerza, tal y como lo establece la carta de Naciones Unidas, y como en la etapa que analiza esta investigación lo establecían de forma indirecta algunos tratados internacionales. Estas normas son de obligatorio cumplimiento tanto por los gobiernos y los ejércitos participantes en el conflicto como por los distintos grupos armados de oposición o cualquier bando participante (Moré, 2007).

En esencia, el DIH irrumpió en las relaciones entre Estados durante la segunda parte del siglo xix, como una réplica de la comunidad internacional a las consecuencias de la guerra. En este sentido, se desarrolló a modo de movimiento no politizado, tomando distancia de las corrientes del pensamiento político en general. La necesidad de limitar los sufrimientos innecesarios de los combatientes heridos y enfermos en el campo de batalla fue el eslabón inicial de una cadena de protecciones acotadas a categorías específicas de personas afectadas por los combates armados.

La incorporación de nuevas categorías de víctimas a los conflictos armados internacionales en la segunda posguerra - como régimen de personas protegidas, herido, enfermos, náufragos y población civil- implicó una evolución constante del derecho aplicable al conflicto armado internacional. Según esta nueva concepción, en un conflicto armado se atendería en un primer momento a los heridos y enfermos en el campo de batalla, posteriormente se regularía la protección a los náufragos, luego se extendió la atención a los prisioneros de guerra y como consecuencia de las traumáticas experiencias vividas durante la segunda guerra mundial, finalmente se reguló la protección debida de la población civil afectada por conflictos armados. En los últimos años se han incorporados nuevas categorías específicas de personas protegidas, también se protege dentro del Diн a determinados grupos de personas vulnerables (mujeres, niños) dentro de situaciones de conflictos armados (Salmón, 2004).

A partir de entonces, en el siglo xIx, los Estados han aceptado un conjunto de normas basadas en la experiencia de la guerra moderna, que mantiene un cuidadoso equilibrio entre las preocupaciones de carácter humanitario y las exigencias militares de los Estados (Halajczuk y Moya, 1999).

El concepto cooperación internacional se define como la ayuda voluntaria de un país (Estado, gobierno local o regional, organización privada) a otro país o conjunto de países. Las poblaciones del país receptor de la ayuda puede recibir la colaboración directamente o bien, a través de su Estado, gobierno local o una organización privada. Los contornos cubiertos por la cooperación internacional son diversos; entre otros, se encuentran: la salud, la educación, mejorar las condiciones ambientales y reducir las diferencias en los sectores económicos y sociales (Gómez, 1999).

A principios del siglo $\mathrm{xx}$, sobre todo durante la segunda década republicana en el marco de la PGM (1914-1918), un ilustre diplomático, político y veterano de la independencia - Cosme de la Torriente y Peraza - comienza a interesarse por la aplicación de determinadas normas del DiH como herramienta para demostrar ante el mundo la personalidad internacional de la república cubana.

De la Torriente y Peraza nació en Matanzas en junio de 1872 y se incorporó al Ejercito Libertador cubano en 1896. Terminó la guerra con el grado de coronel y fue propuesto para el servicio diplomático de la República a partir de 1903, cuando fue nombrado Encargado de $\mathrm{Ne}$ gocios de la Embajada de Cuba en Madrid. Tuvo una estimable participación en la Secretaría de Estado en el primer gabinete de Mario García Menocal entre 1913 y 1914, destacándose en la solución diplomática de la Reclamación Tripartita (Lizaso, 1951).

En las dos primeras décadas republicanas, este jurista intentó demostrar la funcionabilidad de las instituciones republicanas en Cuba, a pesar de la existencia de la Enmienda Platt. Este apéndice constitucional de 1901, le otorgaba el derecho de intervención a los Estados Unidos en la isla de Cuba cuando el gobierno de Washington lo estimase necesario. Además, estipulaba la construcción de estaciones navales y carboneras en territorio nacional 
cubano y omitía la isla de Pinos de la jurisdicción cubana (Márquez, 1941).

De la Torriente y Peraza fungió como Senador por la provincia de Matanzas entre 1917 y 1922, al ser electo el $1^{\circ}$ de noviembre de 1916 . Tomó posesión del cargo el 4 de abril de 1917 y fue electo para un periodo de 8 años que expiraba el primer lunes de abril de 1925 (Sarmiento, 2004). En sus funciones legislativas, fue Presidente y ponente de la Comisión para la Reforma de la Constitución; miembro de la Comisión Codificadora y presidente de la Comisión Nacional de Legislación Bancaria, en la cual presentó un proyecto referente a la reglamentación de bancos y a la creación de un banco nacional de emisión. Además, presidió la Comisión de Relaciones Exteriores en el período que coincidió con la PGM y la posguerra (Sarmiento, 2004).

Se desempeñó como Presidente de la Comisión Nacional Cubana de Propaganda para la Guerra y de Auxilio a sus Víctimas, la cual aportó recursos a gobiernos beligerantes, a las sociedades de la Cruz Roja y a otras instituciones benéficas (esto fue su gran aporte al DIH, derecho que estaba en gestación precisamente en el contexto de la PGM) que se apoyaron en la gestión humanista de este político. A finales de 1918, presentó un proyecto de ley acerca de la fundación de la Liga Internacional de Protección a los Hijos de la Libertad.

En su cargo en la Comisión de Relaciones Exteriores del senado cubano, fue autor $y$ ponente de numerosas leyes sobre el aumento y reorganización del Servicio Exterior de la República - ley que sobrevivió al triunfo de la Revolución Cubana y se aplicó hasta la década del 60- que estabilizó y privilegió el incremento de las misiones diplomáticas de Cuba. En este periodo, se proyectó su vocación diplomática desde la doctrina partiendo de sus participaciones y elaboraciones teóricas en la Sociedad Cubana de Derecho Internacional.

En cuestiones de la vida internacional de la República, uno de los puntos centrales de su pensamiento y acción fue la defensa de la entrada de Cuba en la PGM $y$ la posterior defensa de la firma por Cuba del Tratado de Versalles, elementos que contribuyeron a la confirmación del papel internacional de la isla como país independiente $y$ con personalidad internacional.

\section{EL CONTEXTO NACIONAL E INTERNACIONAL DE LA REPÚBLICA. RELACIÓN DE ESTADOS UNIDOS-CUBA}

Sobre la participación de Cuba en la PGM, no se debe perder de vista el contexto nacional e internacional, $y$ específicamente, el escenario de las relaciones neocoloniales con los Estados Unidos (López, 2009). En abril de 1917, el presidente Mario García Menocal envió un mensaje al Congreso cubano para solicitar la declaración de guerra al imperio alemán. En sesión extraordinaria, el poder legislativo cubano - Senado y Cámara de Representantes- emitió una Resolución Conjunta a través de la cual se declaró la entrada de Cuba en la guerra. En la aprobación de esa resolución jugó un papel esencial la voz senatorial de Cosme de la Torriente y Peraza. Esto no fue una eventualidad, ya que el 5 de abril, el Senado estadounidense había aprobado la declaración de guerra a Alemania.

Posteriormente, se declaró la guerra a Austria-Hungría, ante lo cual el Congreso volvió a emitir otra Resolución Conjunta, que también fue sancionada por García Menocal. Ese mes, Estados Unidos había tomado igual resolución, por lo cual el senador Campos Marquetti propuso que Cuba declarara la guerra también a Turquía y Bulgaria porque no estaban en guerra con Estados Unidos, así se demostraría la independencia de ellos. Los textos de tales documentos muestran los argumentos que se utilizaron en tal coyuntura (López, 2014).

El primero de los mensajes de García Menocal refiere a una de las declaraciones del Gobierno Imperial Alemán dirigidas a las naciones neutrales acerca de sus propósitos de combatir sin previo aviso con todas las armas al comercio $y$ a los barcos neutrales que navegaran en la zona prohibida, por lo que tales barcos lo harían a su riesgo. Por supuesto, eso afectaba las zonas donde había posesiones de los países beligerantes. El presidente cubano manifestó que el país estuvo en desacuerdo ante tales disposiciones, pero Alemania insistió en su plan de guerra submarina $y$ desde el primero de febrero atacó y hundió numerosos barcos mercantes. 
A partir de estos antecedentes, García Menocal pasaba a fundamentar las razones para solicitar la declaración de guerra. Se expusieron las razones que lo unían al gobierno norteamericano, dicho gobierno había protestado durante dos años por la actitud alemana $y$ ante la gravedad de ello, había roto las relaciones diplomáticas. García Menocal argumentaba que:

Cuba no podía ser indiferente a las violaciones del Derecho de Gentes, ni puede en modo alguno, digna $y$ decorosamente, mostrarse ajena o extraña a la actitud noble $y$ valientemente asumida por los Estados Unidos, a cuya nación nos unen sagrados vínculos de gratitud y confraternidad, juntamente con las obligaciones explícitas e implícitas del Tratado de Relaciones Políticas, de 22 de mayo de 1903 (...) y que ha creado y sostiene entre ambos países, por su naturaleza $y$ necesarios afectos, una inteligencia tan íntima que resulta, de hecho, una verdadera alianza que en cualquier tiempo exigiría de Cuba un concurso decidido, pero que la reclama con mayor fuerza en ocasión como la presente, en que los Estados Unidos defienden a toda luz los fueros de la libertad humana, de la justicia internacional, del honor y de la seguridad de las naciones libres e independientes (...) (1917, p. 4).

El mensaje argumentaba que en tal situación Cuba no podía permanecer neutral, ya que esto exigiría a tratar por igual a todas las partes, lo que se contradecía con el sentimiento, con los pactos y las obligaciones con Estados Unidos. A esto añadía que la posición geográfica de Cuba hacía inevitables los conflictos. La declaración de guerra que solicitaba García Menocal involucró, según el texto oficial, “(...) la cooperación decididamente con el Gobierno estadounidense, prestándole toda la asistencia que esté a nuestro alcance, para la defensa de la libertad de los mares, del derecho de los neutrales $y$ de la justicia internacional" (Valdés, 1920, p. 3).

Se hizo incuestionable la necesidad de exponer la decisión del poder cubano en su relación con lo realizado por los Estados Unidos, incluyendo las cuestiones que atañían las gestiones que Cuba debía ejecutar como país beligerante. Este asunto se reiteró en el mensaje del Ejecutivo Al Pueblo de Cuba, así como, en los documentos de diciembre de 1917, relativos a la declaración de guerra a Austria-Hungría. El mensaje presidencial dando a conocer este asunto, fue más conciso que el dirigido al Congreso, se refirió a los agravios que Alemania había inferido a Cuba con sus decisiones, pero no dejó de mencionar la analogía de la declaración cubana con la de Estados Unidos y los vínculos comerciales, de tratados y convenios, también de estrecha confraternidad que existían entre los dos países (Valdés, 1920).

\section{COSME DE LA TORRIENTE Y PERAZA: SU PAPEL EN EL SENADO CUBANO COMO PROMOTOR DE LA COOPERACIÓN INTERNACIONAL}

La etapa de Cuba como país beligerante en la PGm se inició en 1917, en un contexto de dinámicos conflictos internos en el país, motivados por el fraude electoral cometido para la reelección del presidente García Menocal. En este, se definió que la contribución fundamental de Cuba a la guerra residía en la producción de azúcar, por lo que una sacudida interna que afectara a esa industria era inadmisible. Tuvo una amplia repercusión en este periodo, el discurso presentado por Cosme de la Torriente y Peraza ante el Senado El estado de guerra entre la República de Cuba y el Imperio Austro-Húngaro, el cual fue pronunciado en la sesión del 14 de diciembre de 1917:

(...) nuestro proceder ha sido el mismo seguido por los Estados Unidos (...) Cuba solo desea cooperar con los Estados Unidos y con las potencias aliadas para que las condiciones del mundo en el futuro hagan más fácil la vida de los pueblos como el nuestro; para que jamás otra vez un poder enorme como el del Imperio Alemán pueda estrangular la libertad $y$ la independencia de las pequeñas nacionalidades; para que siempre la democracia reine y sea una verdad sobre la tierra; $y$ para cuando termine 
la guerra acaben también los gobiernos tiránicos como el germano. Cuba combatirá a este tipo de gobierno tiránico, no mandando soldados, sino ayudando con todos nuestros recursos a los pueblos que allá luchan (de la Torriente y Peraza, 1917a, p. 23).

En este sentido, la postura para anunciar su adhesión a la incorporación de Cuba a la PGM se caracterizó por lo siguiente: primero, no lo hizo desde una posición bélica sino afincándose en los sólidos argumentos del Derecho Internacional que reinaba en esa etapa; segundo, demostró su defensa teórica de la democracia $y$ el tipo de gobierno liberal en función de una postura internacional de la República y se basó en la doctrina de la gratitud.

Los intereses que se movieron en torno a la participación de Cuba en la guerra necesitaban seguridad y estabilidad en el país, de ahí la alineación del gobierno de Wilson con García Menocal en todo el proceso de la insurrección liberal de febrero de 1917. El Partido Liberal se había levantado en armas contra García Menocal al alegar fraude en diversos colegios electorales y no reconocieron el triunfo que le daba la reelección al Partido Conservador encabezado por García Menocal. Posteriormente, los norteamericanos condenaron la violencia de los liberales en la zona oriental de Cuba. Se planteó que ante los graves acontecimientos mundiales era necesario obviar las diferencias políticas y muchos sectores liberales lo interpretaron como la aceptación del fraude electoral (López, 2014).

Entre las medidas de guerra estuvo la formulación de una política represiva, tal como muestra la suspensión de las garantías constitucionales o la puesta en vigor de la vieja Ley de Orden Público de 1870, o el decreto 1900, del 27 de noviembre de 1917, por el cual se establecía una férrea censura postal -que el Departamento de Estado de los Estados Unidos había solicitado a García Menocal en nota del 20 de noviembre del mismo año-y a la prensa, además prohibía la circulación de cualquier escrito o dibujo que incitara a cualquier acto contrario o de desobediencia a la autoridad o que indujera a huelgas.
De la misma forma, se intentó la aprobación de la ley estableciendo el servicio militar obligatorio, aunque no se logró hasta el 3 de agosto de 1918 por la fuerte oposición que concitó. El debate en torno al servicio militar obligatorio fue promovido por el propio de la Torriente y Peraza, quien desde el Senado trató de promover esta polémica e impopular ley. Esta tuvo como propósito principal reclutar a los jóvenes cubanos con vista a su participación en la guerra; sin embargo, el propio gobierno norteamericano se opuso a esta ley, recordando al gobierno cubano que su función en la participación dentro del conflicto debía limitarse a producir azúcar para los aliados.

El envío a Europa de un contingente de jóvenes cubanos provocó una polémica nacional. De la Torriente y Peraza fue partidario convencido de que la participación de los jóvenes en la guerra era una gran oportunidad para que Cuba mostrase ante el mundo su soberanía, ganando prestigio y reconocimiento internacional. Este era un paso necesario para dejar atrás el lastre de la Enmienda Platt:

Los jóvenes cubanos deben tener el honor que se les presente esta ocasión de servir a la patria figurando en el Ejército (...) Hasta que Cuba entró en esta guerra había en el mundo quienes creían que los cubanos no teníamos una verdadera libertad, una verdadera independencia, ni facultades para resolver sus asuntos internos. Y esa república que algunos han estimado algo recortada por las desgracias de la historia y por las torpezas de los propios cubanos, esa República que tiene en su único Tratado Permanente algunos preceptos, que si alguna vez se han estimado una garantía, en cambio, han servido, para que algunos tratadistas de derecho internacional, entiendan que nuestra nación tiene un poco restringida su soberanía, nunca habrá tenido mejor oportunidad que enviar a sus jóvenes hijos a luchar por la democracia para demostrar que puede vivir sin tales preceptos injerencistas (de la Torriente y Peraza, 1918, p. 3). 
De la Torriente y Peraza promovió el criterio idealista de que los jóvenes combatientes cubanos pudieran influir en la decisión de Estados Unidos de limitar o eliminar la Enmienda Platt. Pero su visión sacrificaría a esa joven generación y esta fue una limitación importante de su interpretación simplista de la vida internacional republicana $y$ de su personalidad. Este político se atrapó en su idealismo liberal burgués que desde su puesto en el Senado, no comprendió las alianzas concretadas entre el imperialismo y el capital doméstico.

En el contexto de la guerra, el gobierno conservador de García Menocal aseguró el ambiente y la eficiencia necesarios, pero también recibía tropas estadounidenses en territorio cubano (supuestamente para entrenamiento), al igual que permitía la presencia de funcionarios de Washington en determinadas labores como por ejemplo, el control de la censura, para lo cual García Menocal había pedido el envío de un oficial que estudiara la posibilidad de implementar en Cuba el sistema electoral de aquel país. En este ambiente, de la Torriente $y$ Peraza privilegiaba en sus enunciados la deuda de gratitud del pueblo cubano hacia los Estados Unidos:

En 1898 nació la deuda de gratitud debido a los triunfos de cubanos $y$ americanos que juntos derrotamos al colonialismo español. Esa deuda de gratitud nos hizo declarar la guerra a Alemania en 1917 ...no podíamos proceder de otra manera; $y$ esa declaración de guerra fue posible porque en la inmensa mayoría de nuestro pueblo aún estaba vivo el ideal que antes lo había llevado a luchar por la independencia $y$ por la libertad, por la democracia y por la justicia, es decir por ideales y sentimientos que no mueren (de la Torriente y Peraza, 1942, pp. 87-88).

Su concepción sobre la gratitud se bifurcó con la justificación de los ideales democráticos y liberales. En este análisis, se debe tener presente el contexto de 1917, en el cual era difícil concebir a Cuba al lado de los Estados Unidos en el conflicto mundial sin el sustento de la democracia ni la libertad como ejes del discurso político liberal. La entrada al conflicto de los norteamericanos y la justificación para que Cuba entrase a este junto con ellos no reflejaba una postura de subordinación total a los Estados Unidos. De la Torriente y Peraza -así, como otros colegas del Senado y la Cámara de Representantes - tenían ideales libertarios y democráticos, aun sin tener la república una independencia absoluta. Por su parte, en el medio liberal-democrático internacional se desaprobó la Triple Alianza conformada por los Imperios Centrales y el Imperio Turco, que cometieron atrocidades a civiles en territorios europeos ocupados y a prisioneros de guerra.

Igualmente se exaltaron criterios positivos acerca de las democracias occidentales de Inglaterra y Francia, aun cuando Inglaterra era una monarquía se le refería como una experiencia inédita en legislación social y anticapitalista bajo los gobiernos laboristas de preguerra. Pero del Imperio Ruso apenas se hablaba y solamente se elogiaba el coraje de sus tropas. Estos criterios recibían amplia cobertura mediática en el mundo a través de los periódicos, las agencias de noticias francesas, la United Press (uP) estadounidense, que controlaban ese mercado y la literatura panfletaria (Crouzet, 1964). Cuba estaba permeada por esta información tendenciosa. Solamente al consultar los principales diarios cubanos de la época como el Diario de La Marina, El Mundo, La discusión y La Lucha se nota la influencia de este tipo de información. En general, en Cuba, en todos los segmentos sociales con algunos gradientes culturales, estaba extendida una matriz de opinión en apoyo a la causa de la Entente. La acción de Cosme de la Torriente y Peraza, así como de otros políticos cubanos, estaba justificada desde ese punto de vista.

\section{EL DERECHO INTERNACIONAL HUMANITARIO DESDE LA VISIÓN DE COSME DE LA TORRIENTE: UTOPÍA Y REALIDAD}

Para consolidar el papel de Cuba en las relaciones internacionales, de la Torriente y Peraza sustentó su concepción sobre la cooperación internacional como medio de sostener su discurso liberal nacionalista. El 14 de diciembre de 1917, pronunció su discurso ante el Senado 
La Cooperación de Cuba en la Guerra, en el cual fundamentó el debate por la aprobación de un proyecto de ley sobre el tema. Volvió a manifestar el criterio de su confianza de la entrada de los norteamericanos en el conflicto y tras ellos Cuba, no por simple subordinación, sino por las estrechas relaciones de amistad que existían entre ambas naciones:

(...) una obligación que no podemos dejar de cumplir: la de entrar con Estados Unidos en toda guerra que los afectare vitalmente como la actual. Pero además aunque no hubiera sucedido nada de lo que acabo de recordar, aunque la República de Cuba se hubiera fundado solo con el esfuerzo de sus hijos, nosotros no hubiéramos tampoco dejar de entrar en esta guerra como lo demuestra lo que está pasando con las otras repúblicas latinoamericanas que han tenido forzosamente, unas que acordarla siguiendo el ejemplo de los Estados Unidos, y otras que rompieron sus relaciones con este, al extremo que quedaran muy pronto muy pocas o ninguna de ellas como neutrales (de la Torriente y Peraza, 1917b, p 3).

Este discurso fue pronunciado después de su regreso de Estados Unidos, donde se reunió con hombres de negocios y políticos que habían manifestado la preocupación por que en Cuba estallara otra revolución como la de 1906. De la Torriente y Peraza refrendó su criterio de que en Cuba con posterioridad a lo ocurrido en 1917, nadie podría perturbar la paz social alcanzada por los cubanos, aun cuando la impronta del fraude electoral todavía rondaba el escenario político cubano y eso preocupaba a autoridades norteamericanas.

(...) entre los cubanos que figuran en la vida pública no hay quien pueda perturbar el territorio de la República para así favorecer directa o indirectamente la causa del Gobierno Imperial Alemán. No hay cubano por menguado que sea, capaz de entenderse con el Gobierno alemán o con sus agentes - o con cualquiera de las naciones aliadas a este- para perturbar nuestro territorio y ayudar así a triunfar los ideales de nuestros enemigos que son contrarios a la democracia y la libertad (de la Torriente y Peraza, 1917b, p 5).

Dentro de su pensamiento político se infiere la relación entre la doctrina de la personalidad internacional, la vida internacional de la república y el compromiso con la democracia $y$ los valores de la libertad. Se está en presencia de un senador que ya se encuentra en una etapa de maduración de algunos de sus postulados teóricos, pero su análisis se reduce a los cubanos de la vida pública y excluye al pueblo, en su mayoría analfabeto, que no entendían el contexto de un conflicto mundial. Por último, dejó delimitada su concepción de cooperación internacional, basada en la experiencia de que la cooperación cubana en la guerra estaría concentrada no en hombres y armas, sino en la producción de azúcar:

(...) desarrollando hasta el grado que sea necesario nuestra producción azucarera, desarrollándola en condiciones tales y en tal cuantía que puedan necesitar las naciones aliadas para sus poblaciones en Europa o en América y para sus ejércitos, la encuentren aquí en grandes cantidades $y$ a precios moderados, para que sus flotas mercantes no tengan que trasladarse a lugares remotos del globo en busca de una parte de ese indispensable recurso que es el azúcar. Y cooperaremos además si hacemos toda clase de esfuerzo para que el suelo cubano y su industria nacional puedan producir una cantidad de esos productos que aun importamos y que los americanos tienen que enviar a Europa para el sostenimiento de los ejércitos y de las poblaciones aliadas, productos que a diario luchamos para que se nos vendan en los Estados Unidos, siendo cada día mayores las dificultades que se presentan para su envío a Cuba...invito a mis compañeros a votar de manera favorable el Proyecto de Ley de Cooperación de Cuba en la Guerra... con una votación favorable fortalecemos la unión de todos los 
cubanos por el triunfo de la causa aliada, que es la causa que ha llevado a Estados Unidos a la guerra, que será nuestro triunfo $y$ a la vez implicará el fortalecimiento de la personalidad de la República (de la Torriente y Peraza, 1917b, p. 6).

Las ideas que expresó reflejaron las amplitudes de miras en las que se movió su praxis, desde el incentivo al desarrollo de la industria azucarera hasta la diversificación de producciones nacionales, las cuales contribuyeron a un amplio debate senatorial sobre la cooperación de Cuba en el conflicto, cuestión que no simplificó el problema de armamentos y hombres. De la Torriente y Peraza demostró una dinámica reformista social en su ideología, pero no excluyó nunca la incidencia de la paradigmática sociedad norteamericana y su impacto en las posturas políticas. Por otro lado, se proponía a expensas del conflicto, preservar los mercados estadounidenses y euro occidentales para el azúcar cubano y conquistar el mercado interno para los productores nacionales de bienes de consumo, apartados de este por las importaciones estadounidenses a raíz del ejercicio del Tratado Comercial de 1902.

Teóricamente, se apoyó en los criterios de Gabriel Hanotaoux, importante jurista, historiador y diplomático francés que desde principios del siglo xx desarrolló una doctrina de la cooperación internacional como eje esencial del desarrollo de la personalidad internacional de una República.

(...) le corresponde a los países pequeños $y$ de efímera vida internacional, desarrollar las potencialidades de la cooperación internacional; pero en el marco de un conflicto internacional no debe potenciar su mentalidad guerrerista, más bien buscar la conservación y venta de sus productos en los mercados que están en guerra (Hanotaoux, 1917, p. 22).

Hanotaoux fue uno de los teóricos europeos que más influyó en la formación del pensamiento humanista de la diplomacia cubana sobre la cooperación internacional. Este ilustre historiador y diplomático francés (1853-1941) se convirtió en 1918 en Presidente de Honor del Comité Francia-América y tuvo grandes consideraciones con el servicio internacional prestado por Cuba a las víctimas de la PGM. La base esencial de su concepción fue no potenciar la guerra en medio de un conflicto, sino potenciar los bienes hacia el mercado internacional, contribuyendo a formar un amplio frente de productos que contribuyeran a paliar la situación en el escenario del conflicto.

Por otro lado, se convirtió en uno de los ideólogos cubanos defensor de la cooperación internacional en la guerra $y$ en la posguerra. Además, fue uno de los diplomáticos europeos que reconoció el papel de Cuba en la vida internacional. Asimismo, fue miembro de la Academia Francesa y dedicó parte de su obra teórica a los problemas internacionales. En los últimos años de su vida, a finales de la década del 30, reconoció el papel de Cosme de la Torriente y Peraza en el apoyo a las víctimas de la PGm y a sus familiares (Hanotaoux, 1939, p. 11).

Siguiendo el paradigma de Hanotaoux, de la Torriente y Peraza pretendió beneficiar al máximo con las secuelas de la guerra a los capitales domésticos y al estadounidense -el cual disponía de la infraestructura de transporte, comunicaciones $y$ almacenaje- de las relaciones en el mercado mundial, las compañías aseguradoras y las mayores unidades agroindustriales de la Isla. Del mismo modo, entre 1917 y 1918, presentó un Proyecto de Ley referente a la Formación de una Asociación Internacional para la Protección de los Huérfanos de la Guerra, que incluso tuvo un impacto internacional, sobre todo en Francia e Inglaterra. Estas concepciones de la cooperación internacional y la formación de asociaciones internacionales humanitarias se basaron además en las consideraciones teóricas de otros pensadores y juristas como James Brown Scott (1866-1943). Este jurista norteamericano reconocía el papel del derecho internacional como instrumento que permitía elevar la capacidad de la personalidad jurídica internacional de las pequeñas naciones que como Cuba luchaban por insertarse en el escenario mundial. 
Brown Scott abogaba además por el reconocimiento del papel de las pequeñas naciones en las relaciones internacionales. Por otra parte, fue partidario durante la PGM de concentrar a los huérfanos del conflicto en países estables políticamente para su atención. Desde la perspectiva institucional, Brown Scott propuso la creación de Tribunales Internacionales de Justicia, basados en el modelo de la Corte Suprema de los Estados Unidos y fundó la American Society International Law (Scarfi, 2014).

En el Senado cubano, de la Torriente y Peraza se dedicó además a prestarle atención a problemas internos - como los de la inmigración, la expansión de los cultivos varios, el reconocimiento del papel de la mujer en la política, el derecho al voto femenino, el derecho al divorcio y el derecho a comer de los pobres-que incidieron en la vida internacional de la República y facilitaban la práctica de la cooperación internacional, dándole a sus postulados un marcado carácter reformista e internacionalista desde la jurisprudencia; por ejemplo, el 30 de julio de 1917, coincidiendo con el auge que experimentaba la exportación del azúcar cubano en el contexto de la PGM, se opuso sin éxito a una propuesta de ley a favor de la libre importación de braceros hasta dos años después de terminada la contienda bélica. En su discurso Inmigraciones Peligrosas defendió que:

La inmigración libre de braceros antillanos afectará la composición étnica de la Nación...me opongo a la duración del plazo de residencia y a las repercusiones negativas que el ambiguo plan tendrá en los salarios de los cubanos...además me pregunto ¿Cómo las autoridades de inmigración harán para hacer salir esta incómoda población de la isla que en teoría es estacionaria pero que la práctica nos dirá que permanecerán en Cuba por mucho tiempo sin naturalizarse del todo, agravando los problemas sociales de Cuba como la desocupación? (de la Torriente y Peraza, 1917c, p. 11).

De la Torriente y Peraza separó los inmigrantes en "peligrosos" (los procedentes de las Antillas menores) y "buenos" (españoles y blancos) en general (De la Torriente y Peraza, 1917c). Consideró que el inmigrante español debía ser protegido por las leyes cubanas para su permanencia y para la reproducción de su familia. Acudió a los argumentos esgrimidos por el pensamiento liberal cubano progresista del siglo xix que abogaba porque la población blanca podría cultivar $y$ fomentar la pequeña $y$ mediana propiedad - sobre todo rural de cultivos varios- para equilibrar los efectos en la sociedad de la gran propiedad azucarera.

Otros proyectos de leyes fueron elaborados por este político en 1917, por ejemplo, propuso una Ley sobre Arriendo u Ocupación Forzosa de Terrenos con Destino a Zonas de Cultivo, la cual se fundamentó en los argumentos de un nacionalismo económico, ya que tuvo como trasfondo la diversificación de cultivos; además defendió teóricamente la concepción liberal de arriendo de tierras baldías, necesarias para el crecimiento productivo (de la Torriente y Peraza, 1917b). Es evidente que proyectó utilizar la fuerza coercitiva del Estado para incorporar los terrenos baldíos privados $y$ estatales a relaciones de propiedad agrarias en que predominaba el latifundio azucarero, agregándole ahora un elemento poco desarrollado hasta ese momento pero propiciado entonces por la favorable coyuntura del mercado interno: el desarrollo de latifundios productores de alimentos.

En el marco de su labor legislativa, de la Torriente y Peraza desplegó su concepción de ampliar la vida internacional a través de la diversificación de las relaciones diplomáticas y culturales con otros países como base de sus concepciones primarias de la aplicación del humanismo al derecho internacional.

Un conjunto de discursos promovió esa idea entre lo que destacó la amplitud de miras con respecto a los países: Italia, Bélgica, Portugal, Venezuela y Uruguay. Además, en sus intervenciones, promovió la idea de ascender al rango de Embajada a las delegaciones de Cuba en esos países, aumentando el número de diplomáticos cubanos. También, difundió la idea de celebrar el Día de la Fiesta Nacional de dichas naciones en Cuba. Con anterioridad, el Senado de la República a propuesta del político, había declarado Día de Fiesta Nacional las fechas de 
los Estados Unidos de América y Francia (4 de julio y 14 de julio respectivamente), hechos que sustentaban el intento de consolidar la débil personalidad internacional jurídica de esta república (de la Torriente y Peraza, 1922e). En el caso específico de las relaciones con Italia manifestaba lo siguiente:

(...) Propongo dirigir un mensaje al Senado italiano en este memorable día del tercer aniversario de entrada de esa poderosa nación en la Guerra, guerra en la cual nosotros hemos entrado también, para luchar por la libertad, por la democracia y por el derecho. En este saludo presentamos nuestro entusiasmo y admiración por esa gran nación, ya que nunca olvidaremos que en los días tristes posterior a la muerte de nuestro Lugar Teniente General Antonio Maceo, la Cámara de Diputados italiana hizo constar en sesión inolvidable su pesar por la muerte del héroe. Que hagamos expresión de estos sentimientos en el Mensaje, es algo en que todos los cubanos estaremos de acuerdo, porque Italia no es para nosotros solamente una nación generosa, que en un tiempo expresó sus simpatía por nuestra libertad, sino además porque consagró en su parlamento un recuerdo a Maceo, nuestro gran Maceo; además Italia es la Madre de nuestra cultura latina...Propongo además en gratitud a esto, enviar un Mensaje de solidaridad al Senado italiano y proponerles a nuestros hermanos de cultura en esa nación ampliar nuestros lazos diplomáticos; elevar el rango y jerarquía de nuestra legación en ese país para consolidar nuestra capacidad de actuar en la vida internacional (de la Torriente y Peraza, 1922, p. 450).

También, de la Torriente y Peraza reconoció como parte de la inserción de Cuba en la vida internacional, su aporte a la derrota de Alemania y sus aliados:

El acto heroico, glorioso y sublime del pueblo belga oponiéndose al paso de los ejércitos alemanes por su territorio, puede decirse que salvó a la civilización que pertenecemos...la heroica resistencia de Bélgica permitió la recuperación de los franceses...Proponemos además en este discurso declarar Día de Fiesta Nacional el 21 de julio por celebrarse el octogésimo octavo aniversario de la independencia de Bélgica (de la Torriente y Peraza, 1922, p. 456).

A partir de este contexto, Bélgica comenzó a considerarse por la diplomacia cubana como nación amiga en la vida internacional. En consideración a las relaciones cordiales que se establecieron con este país europeo, una céntrica calle habanera cambió su nombre por Avenida de Bélgica. El 21 de julio de 1918, se celebró por primera vez en Cuba, el Día Nacional de Bélgica y fue invitada una delegación militar a La Habana.

Como resultado del Proyecto de Ley de Cooperación Internacional propuesto por el senador, se creó en 1918, la Comisión Cubana de Propaganda por la Guerra y Auxilio a las Víctimas, de la cual fue elegido Presidente. Aunque los trabajos de esa Comisión terminaron hacia 1920, de los dos millones cuatrocientos mil pesos anuales que se pidieron al Ejecutivo, se invirtó un millón cien mil en el auxilio a las víctimas del conflicto mundial. De ese total, Cuba le donó la mayor parte a Francia - trescientos mil- además de distribuir una parte a otros países como Bélgica, Italia, Estados Unidos, Gran Bretaña, Serbia, Grecia, entre otros.

En la práctica, la gestión del senador fue meritoria, hizo todo lo posible por reunir fondos para hacerlo llegar a los principales países europeos aliados afectados por el conflicto. En comunicación con el Presidente del Comité de la Cruz Roja de Bélgica, de la Torriente y Peraza informó el envío de 17485 francos, equivalentes en la época a 30000 pesos cubanos (de la Torriente y Peraza, 1922).

A pesar de ser un representante de la oligarquía cubana, la verdad histórica supera a la utopía humanista en de la Torriente y Peraza en este contexto. El senador matancero promovió la participación activa de Cuba en las relaciones internacionales al proponer la formación 
de una Asociación para la protección de niños huérfanos de la guerra, iniciativa que caló en varios países.

En diciembre de 1918, De la Torrente y Peraza presentó ante el Senado su discurso planteando a nombre de la República de Cuba, en el cual proponía a todas las potencias aliadas en la guerra contra los imperios centrales de Europa y aquellas otras que rompieran sus relaciones diplomáticas y militares con estos, la formación de una asociación internacional para la protección, amparo y educación de los niños desvalidos, cuyos padres hubieran fallecido combatiendo en las filas de los aliados por la libertad del mundo (de la Torriente y Peraza, 1922).

Fue una propuesta esencial para comprender la dinámica que alcanzó en esos momentos la búsqueda de una presencia internacional $y$ prestigio del servicio exterior cubano. Además, el senador divulgó en ese discurso un amplio plan internacional que se sustentaba en el más profundo humanismo liberal de la época:

La protección a los huérfanos se extendería hasta la edad que pudieran valerse por sí mismo. Para lograr este empeño, se necesita la creación de un fondo internacional que afrontarían todos aquellos estados contratantes en la proporción y cuantía que permitieran su población, y su riqueza pública (de la Torriente y Peraza, 1922, p 3).

Esta propuesta humanista fue enviada al Ministerio de Exteriores de Francia y causó gran impacto en la opinión pública de ese país $y$ en otros países aliados. El pensamiento y la acción diplomática de Cosme de la Torriente y Peraza se basaron de la corriente humanista en el contexto final de la PGM. Asimismo, mostró un prototipo concreto del progreso de Cuba en la vida internacional. En 1919, el político pidió autorización ante el Senado de la República para recibir las condecoraciones que Francia, Venezuela, Portugal y Bélgica le concedieron por sus valiosos aportes al auxilio de las víctimas y sus acciones en favor de la paz mundial. Entre el 5 y el 23 de julio de 1919, recibió La Legión de Honor de Francia, la Gran Cruz de Orden de la
Corona de Bélgica, la Gran Cruz de Honor de la Cruz Roja de Portugal y la Orden del Libertador de Venezuela Simón Bolívar (de la Torriente y Peraza, 1938).

\section{CONCLUSIONES}

Cosme de la Torriente y Peraza fue un destacado político, diplomático y abogado cubano que vivió la transición colonial a la neocolonial. En este marco se destacó por ser una de las figuras más emblemáticas del servicio diplomático de la República y del Senado.

Desde la perspectiva del derecho internacional, en los marcos de la PGM, se destacó por su apoyo a la aplicación de determinadas normativas del DiH, específicamente la dimensión humanista de la cooperación dentro de la guerra y el auxilio a las víctimas de este conflicto, aspecto poco estudiado por la historiografía cubana, incluso desde la configuración del derecho.

Esta investigación introduce elementos novedosos en este campo, ya que se acerca al aporte de uno de los internacionalistas cubanos que intentaron desde las posiciones del poder jurídico y político demostrar que las relaciones exteriores de la República funcionaron a pesar de la existencia de la Enmienda Platt y de las presiones norteamericanas a la soberanía cubana. Sus actos en el Senado republicano desde un sustento del liberalismo introdujeron una cuota de utopía pero a la vez pragmática, al momento de aplicar el derecho internacional en el contexto cubano de la PGM.

De la Torriente y Peraza fue precursor de la utilización de determinadas normativas del рін (en proceso de desarrollo en el marco de la PGm Guerra Mundial). En aquella coyuntura, muchas de esas normativas se consideraban utópicas debido al contexto complejo de las relaciones con los Estados Unidos y al escaso desarrollo del DiH, pero los intentos para aplicarlas por parte de Cosme de la Torriente y Peraza sirvieron para demostrar el lado humanista de las relaciones internacionales de la república cubana afectada por el obstáculo injerencista de la Enmienda Platt. Esta gestión ocasionó el reconocimiento de amplios sectores sociales de la república, pero también 
de varios países que concibieron el aporte a la construcción de la diplomacia en un Estadonación del Caribe.

\section{REFERENCIAS}

Crouzet, M. (1964). Historia General de las Civilizaciones. La epoca Contemporánea. La Habana, Cuba: Editorial Pueblo y Educación.

De la Torriente y Peraza, C. (1917a). El estado de guerra entre la República de Cuba y el Imperio Austro-Húngaro, La Habana, Cuba: Siglo xx.

De la Torriente y Peraza, C. (1917b). La Cooperación de Cuba en la Guerra; La Habana, Cuba: Imprenta y Papelería de Rampla y Bouza y Co.

De la Torriente y Peraza, C. (1917c). Inmigraciones peligrosas, La Habana, Cuba: Imprenta y Papelería de Rambla, Bouza y Ca.

De la Torriente y Peraza, C. (1917d). Proposición de Ley sobre Arriendo u Ocupación Forzosa de Terrenos con Destino a Zonas de Cultivo, La Habana, Cuba: Imprenta y Papelería de Rambla, Bouza y Ca.

De la Torriente y Peraza, C. (1918). Sobre el Servicio Militar Obligatorio, La Habana, Cuba: Imprenta y Papelería de Rambla, Bouza y Compañía.

De la Torriente y Peraza, C. (1922). Cuba en la vida internacional (Discursos). La Habana, Cuba: Imprenta y Papelería de Rambla y Bouza.

De la Torriente y Peraza, C. (1938). Cuarenta años de mi vida. La Habana, Cuba: Imprenta Siglo xx.

De la Torriente y Peraza, C. (septiembre de 1942). Cuba, la guerra y el gobierno de unidad nacional. Revista de la Habana, I, año I, 87-88.

García Menocal, M. (diciembre de 1917). Mensaje al Congreso de la República sobre el conflicto actual en Europa. Revista Bohemia, xI, 12-16.

Gómez Galán, Miguel. (1999). El sistema internacional de cooperación al desarrollo. Madrid, CIDEAL.
Halajczuk, Bohdan T y Moya Domínguez, María Teresa del R. (1999). Derecho Internacional Público. Buenos Aires, Argentina: Editora Comercial Industrial y Financiera,

Hanotaoux, G. (1917). Las bases de la cooperación internacional. París, Francia: Ediciones Plaza.

Hanotaoux, G. (1939). Cosme de la Torriente y la Sociedad de Naciones. París, Francia: Ediciones Mediterráneo.

Lizaso, Félix. (1951). Cosme de la Torriente. Un orgullo de Cuba, un ejemplo para los cubanos. La Habana, Cuba: Editorial Lex.

López, F. (2009). Cuba seis décadas de historia. 1899-1959. La Habana, Cuba: Editorial Félix Varela.

López, F. (2014). 1917. Cuando Cuba entró en la Primera Guerra Mundial. La Habana, Cuba: Editorial de Ciencias Sociales.

Márquez Sterling, Manuel. (1941). Proceso histórico de la Enmienda Platt.1897-1934, La Habana, Cuba: Siglo xx.

Moré, Y. (mayo de 2007). La interrelación del derecho internacional $y$ el derecho interno en Cuba. Revista Colombiana de Derecho Internacional, 9, 371-394.

Salmón, E. (2004). Introducción al Derecho Internacional Humanitario, Perú: Instituto de Democracia y Derechos Humanos.

Sarmiento, P. (2004). El pensamiento politico de Cosme de la Torriente y Peraza. (Tesis de Maestría en Historia y Cultura en Cuba). Universidad de Holguín, Cuba.

Scarfi, J.P. (2014). El imperio de la ley. James Brown Scott y la construcción de un orden jurídico interamericano, Buenos Aires, Argentina: Fondo de Cultura Económica.

Valdez, L. (1920). El comercio exterior de Cuba y la Guerra Mundial. Habana, Cuba: Avisador Comercial.

Fecha de ingreso: 28/11/2016 Fecha de aprobación: 22/06/2017 
